\title{
Prevelence of Cervical Ribs in a Nigeriapopulation
}

\author{
Ebeye O Abimbola, Apare A Willido. \\ Department of anatomy and cell biology, college of health sciences Delta State University, Abraka
}

\begin{abstract}
Background: Cervical ribs are congenital variants that are known to cause thoracic outlet syndrome or brachial plexopathy in up to $10 \%$ of the affected individuals. Cervical ribs are an important cause of neurovascular compression at the thoracic outlet. Previous studies have shown the prevalence of cervical ribs to be between 0.05-3\%, depending on the sex and race of the population studied.

Objective:The aim of this study was therefore to determine the prevalence of cervical rib in Urhobo's as well as its relation to gender.

Materials and method: This study examined 500 (245 males and 255females) cervical spine radiographs to determine the prevalence of cervical ribs in a Nigeria population of mixed sex and ethnicity.

Results: This study found three cervical ribs, one of which was bilateral and two unilateral. The overall prevalence of cervical ribs was $0.6 \%$ (3/500) of the population with a higher rate in females $0.78 \%(2 / 255)$ compared with males $0.4 \%$ (1/245). Of the 3 individuals with a cervical rib, one was on the left, one occurred on the right and the last was bilateral.

Conclusion:cervical rib can however, be highly significant clinically, with patients presenting with symptoms of neurovascular compromised due to compression on the neurovascular bundle. It is therefore recommended that in differential diagnosis of pain syndromes of the neck, the possibility of cervical rib should not be ruled out.

Key words: Cervical ribs, Urhobos, Prevalence.
\end{abstract}

\section{Introduction}

A cervical rib in humans is an extra or additionalrib asagainst the usual twelve ribs, sometimes it is known as neck ribs. ${ }^{1}$ Cervical rib arises from the seventh cervical vertebra or it might simply be an elongation of the transverse process of the seventh cervical vertebra. ${ }^{2}$ Itis generally seen only on one side of the body, more often on the right. It may be a complete or partial rib. ${ }^{3}$ Their presence is a congenital abnormality located above the normal first rib.This condition is present in approximately 1-2\% of the population. ${ }^{4}$ It is caused by a congenital defect during bone formation in even rarer cases; an individual may have two cervical ribs. ${ }^{3,4}$ These ribs are commonly found in reptiles but rarely in humans because spinal growth in humans is faster than upper limb growth and this results in the oblique angulation of the spinal nerves of the limb bud interfering with cervical rib formation. ${ }^{5}$

Cervical rib is usually asymptomatic and is detected when a chest or neck X-ray is taken for some other purposes. ${ }^{6}$ The diagnosis may be confused with carpal tunnel syndrome, cervical disc prolapsed and neuritis of the ulnar nerve supplying part of the forearm and hand. ${ }^{3}$ In other cases the condition produces symptoms in middle age due to sagging of shoulders and decline of muscle tone.Symptoms are seen in women more often than in men. The symptoms occur due to the rib pressing on the nerves or blood vessels, as they go from the spinal column to the arm.Sensory symptoms like pain and tingling numbness are complained of in the forearm and hand, especially the inner side corresponding to the little finger.Motor symptoms include weakness of the arm and hand and impaired fine movements like writing and sewing.If the blood vessels like the subclavian artery are compressed, there may be bluish discolouration of the skin of that limb due to diminished blood supply or in rare cases frank gangrene of the fingers and the pulse at the wrist may be weak or absent. ${ }^{3}$

Cervical rib has been established to be sex and race specific therefore several researchers have looked at the incidence of cervical rib in various races and ethnic groups.In Americans prevalence rate of cervical rib is $0.5-1 \%{ }^{5}$ Incidence of cervical rib in the white British population and in the Asian population was found to be $5.9 \%$ and $24.9 \%$ respectively. ${ }^{7}$ Brewin et al (2009) conducted a study on prevalence of cervical rib in London and found an overall incidence of $0.74 \%$ with a higher rate in females compared to males. ${ }^{8}$ In a study among Malawian population Ebite et al (2004) recorded an overall incidence of $0.58 \%$, a higher incidence was also found in females compared to males. ${ }^{2}$ In (2012)Ani et al studied cervical rib prevalence in a Nigeria population and recorded an overall prevalence of $0.7 \%$ with a higher incidence in females compared to males. ${ }^{9}$

Cervical ribs having been established to be sex and ethnic based and despite the clinical importance of cervical rib, scanty literature exists on its incidence in southern part of Nigeria. The aim of this study is therefore to determine the prevalence of cervical rib in the $10^{\text {th }}$ largest ethnic (Urhobo's) group in Nigeria as well as its relation to gender. 


\section{Material And Methods}

A retrospective study was carried out using technically adequate anteroposterior cervical spine radiographs of indigenous adult Urhobos (245 males, 255 females, age ranged between 19-60 years). X-rays were collected from Eku government hospital and Warri central hospital. Each radiograph was placed on an Xray viewer to assess the presence or absence of true cervical rib. The following criteria were used to identify a cervical rib as described by Viertel et al. ${ }^{10}$

- The rib must abut the transverse process of the $7^{\text {th }}$ cervical vertebra which is seen to project caudally or horizontally from the vertebra, rather than the transverse process of the first thoracic vertebra which extends diagonally upwards from its point of origin.

- A well-developed cervical rib must be separated from but articulate with the transverse process of C7. If fused with the vertebra and longer than the $\mathrm{T} 1$ transverse process, was classified as poorly developed or incomplete.

- It must have no connection with the manubrium sternum although it may form a synostosis with the first rib thus distinguishing a cervical rib from a rudimentary first rib.

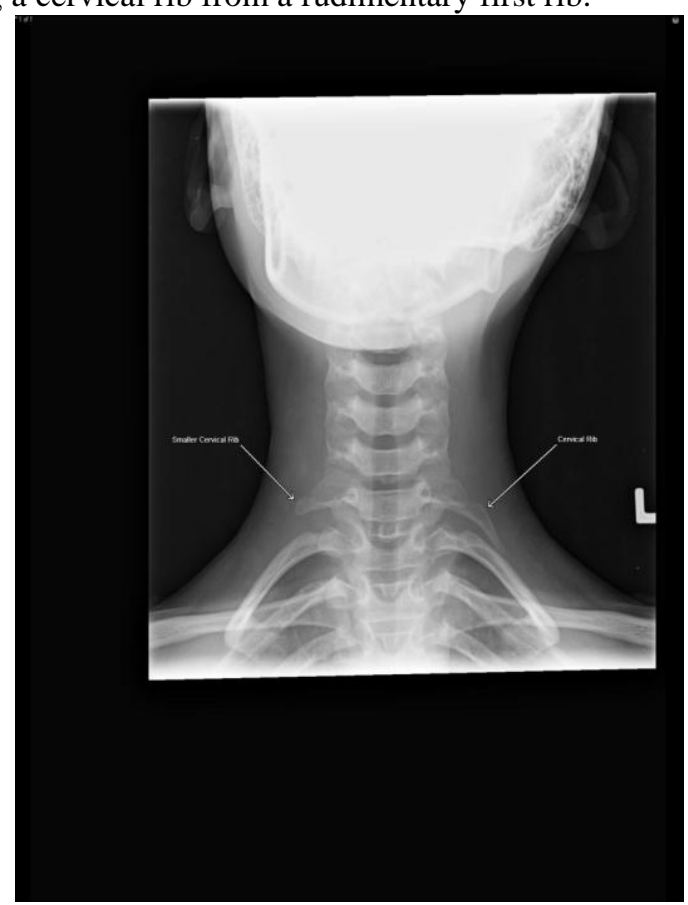

Frontal radiograph of the neck reveals bilateral ribs articulating with the $\mathrm{C} 7$ transverse processes. (OPEN ACCESS RADIOLOGY EDUCATION 2013)

\section{Results}

Frequency of cervical ribs in the Urhobo population

\begin{tabular}{|l|l|l|l|}
\hline & Total no (\%) & Male no (\%) & Female no (\%) \\
\hline Total sample & 500 & 245 & 255 \\
\hline Prevalence of cervical ribs & $3(0.6 \%)$ & $1(0.4 \%)$ & $2(0.78 \%)$ \\
\hline Bilateral cervical ribs & $1(0.2 \%)$ & - & $1(0.39 \%)$ \\
\hline Unilateral cervical ribs & $2(0.4 \%)$ & $1(0.4 \%)$ & $1(0.39 \%)$ \\
\hline
\end{tabular}

The table above reveals a prevalence of $0.6 \%$ (3/500) was found out from the study. The prevalence for males is $0.4 \%(1 / 245)$ and $0.78 \%(2 / 255)$ was recorded for females. Of the three radiographs with cervical ribs, one was found on the right, the other on the left and last was bilateral.

\section{Disscussion}

Previous studies have reported a wide range of values for cervical ribs prevalence, it has also been associatedwith congenital brachial plexus palsy and brachialplexopathy. ${ }^{11,12}$ In human an increasing body of evidence has linked the frequency of cervical rib to still birth, other malformation and early childhood cancers. Of the 500 radiographs studied, cervical ribs were found in $0.6 \%$ (3/500) of the population studied.The study included $245(49 \%)$ males and $255(51 \%)$ females. Cervical ribs occurred twice as often in women $(66.7 \%)$ than men $(33 \%)$ as in prior studies. ${ }^{2,9}$ the result of these study also agrees with previous study as the value gotten for women is approximately twice that of males. Race also appears to be afactor in determining the prevalence in a large population. Four cervical ribs in 3 patient radiographs were found. Moreover, (2/3) of patients with 
cervical ribs had a unilateral rib, while the remaining patient hadbilateral cervical ribs. This also agrees with previous studies. This study has shown that the frequencyof true cervical rib in Urhobo's is consistent with reports from previous studies on other population groups.Brewin(2009) reported a prevalence of $0.74 \%$ in London, Ani(2012)reported an incidence of $0.7 \%$ in a Nigeria population, Ebite (2007) reported prevalence of $0.58 \%$ in Malawians and Ray (1998) reported 0.5-1\% in Americans. The result of the present study is consistent with previous ones except for the study of Tryfonidis et al who recorded a higher incidence. These differences might be based on ethnicity. The clinical importance of cervical rib is sometimes overlooked; as most cases are asymptomatic.It can however, be highly significant clinically, with patients presenting with symptoms of neurovascular compromised due to compression on the neurovascular bundle. It is therefore recommended that in differential diagnosis of pain syndromes of the neck, the possibility of cervical rib should not be ruled out.

\section{Reference}

[1]. Galis F (1999). "Why do almost all mammals have seven cervical vertebrae? Developmental constraints, Hox genes, and cancer". $J$. Exp. Zool.285 (1): 19-26.

[2]. Ebite L.E, Igbigbi P.S,Chisi J.E (2007). Prevalence of true cervical rib in adult Malawian population.J. Anat Sci.1.(1) 7-9.

[3]. NisreenNakhoda (2013). Cervical rib - Causes, symptoms and treatment. Common ailment, health directory.

[4]. Moore K.L. (2010). Clinically Oriented Anatomy 6th Ed. Lippincott Williams \& Wilkins. Pp 460

[5]. Rayan G.M. (1998): thoracic outlet syndrome. J shoulder Elbow Surg 7: 440-451.

[6]. Sander R.J \& Hammond S.L (2002). Management of cervical ribs and anomalous first ribs causing neurogenic thoracic outlet syndrome. J VascSurg 36: 51-56.

[7]. Tryfonidis M, Anjarwalla N and Cole A:Incidence of Cervical Rib in the White British Population and Direct Comparism with the incidence in the Asian Population: A radiological study. J Bone Joint Surg Br 2010 vol. 92-B no. SUPP IV 499

[8]. Brewin J, Hill M, Ellis H.The prevalence of cervical ribs in a London population.Clin Anat. 2009 Apr;22(3):331-6. doi: 10.1002/ca.20774

[9]. Ani CC, Adegbe EO, Ameadaji M, Gabkwet (2012).A Cervical Rib Variant in a Nigerian PopulationJos Journal of Medicine Vol 6, No 1

[10]. Viertel VG, Intrapiromkul J, Maluf F, Patel NV, Zheng W, Alluwaimi F, Walden MJ, Belzberg A, Yousem DM (2012). Cervical Ribs: A Common Variant Overlooked in 10.3174/ajnr.A3143.

[11]. Becker MH, Lassner F, Bahm J, et al. The cervical rib: a predisposing factor forobstetric brachial plexus lesions. J Bone Joint Surg Br 2002;84:740-43

[12]. Desurkar A, Mills K, Pitt M, et al. Congenital lower brachial plexus palsy due to cervical ribs. Dev Med Child Neurol2011;53:18890 